\title{
Nanomedicine Fabricated from A Boron-dipyrromethene (BODIPY)-Embedded Amphiphilic Copolymer for Photothermal-Enhanced Chemotherapy
}

Jie Shen,,${ }^{* \dagger}$ Qiwen Wang, ${ }^{\dagger}$ Yuanyuan Lv,${ }^{\dagger}$ Jingyin Dong, ${ }^{\dagger}$ Guida Xuan,,${ }^{\dagger}$ Jie Yang,,${ }^{*}{ }^{\S}$ Dan Wu,${ }^{\perp}$ Jiong

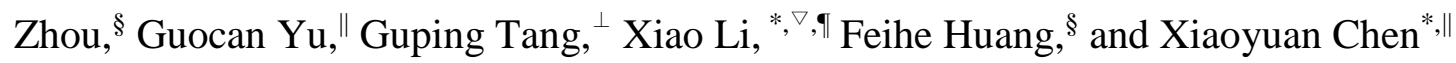

${ }^{\dagger}$ School of Medicine, Zhejiang University City College, Hangzhou 310015, P. R. China shenj@zucc.edu.cn

${ }^{*}$ Heart and Vascular Center, The First Affiliated Hospital, School of Medicine, Zhejiang University, Hangzhou 310003, Zhejiang, P. R. China

${ }^{\S}$ State Key Laboratory of Chemical Engineering, Center for Chemistry of High-Performance \& Novel Materials, Department of Chemistry, Zhejiang University, Hangzhou 310027, P. R. China jieyang@zju.edu.cn

${ }^{\perp}$ Department of Chemistry, Institute of Chemical Biology and Pharmaceutical Chemistry, Zhejiang University, Hangzhou 310027, P. R. China

" Laboratory of Molecular Imaging and Nanomedicine, National Institute of Biomedical Imaging and Bioengineering, National Institutes of Health, Bethesda, Maryland 20892, United States

\section{shawn.chen@nih.gov}

${ }^{\nabla}$ Women's Reproductive Health Laboratory of Zhejiang Province, Women's Hospital, Zhejiang University School of Medicine, Hangzhou, Zhejiang 310006, China

"I The Department of Gynecologic Oncology, Women's Hospital, Zhejiang University School of Medicine, Hangzhou, Zhejiang 310006, China 5198008@zju.edu.cn

\section{Electronic Supplementary Information (13 pages)}

$\begin{array}{ll}\text { 1. Materials and methods } & \mathrm{S} 2\end{array}$

2. Synthesis of $\boldsymbol{M P E G}-\boldsymbol{b}-\boldsymbol{P L A}-\boldsymbol{B O D I P Y}$ S5

3. UV-vis absorption spectrum of BODIPY $\quad \mathrm{S} 10$

$\begin{array}{ll}\text { 4. In vitro drug release } & \mathrm{S} 10\end{array}$

5. Cytotoxicity evaluation $\quad \mathrm{S} 11$

6. In vivo photothermal effect $\quad \mathrm{S} 11$

$\begin{array}{ll}\text { 7. In vivo tumor penetration } & \mathrm{S} 12\end{array}$

8. Histopathology and immunohistochemistry of tumors $\quad \mathrm{S} 12$

9. Body weight analysis $\quad$ S13

10. Histopathology of organs $\quad$ S13 


\section{Materials and methods}

All reagents were commercially available and used as supplied without further purification. ${ }^{1} \mathrm{H}$ NMR spectra were recorded on a Bruker Avance III-300 spectrometer with internal standard TMS. UV-vis absorption spectra were recorded by using a Shimadzu UV-2501 spectrophotometer. Transmission electron microscopy (TEM) images were taken by a HT-7700 transmission electron microscopy (Hitachi, Japan). The particle size was performed by dynamic light scattering (DLS) on the Zetasizer (Nano ZS, Malvern Instruments, Worcestershire, UK). The drug release of DTX was analyzed using a highperformance liquid chromatography (HPLC) system (1220 Infinity LC, Agilent, Santa Clara, CA, USA).

Cells and animal model. The human non-small cell lung cancer cell line A549 was acquired from the American Type Culture Collection (ATCC, MD, USA). A549 cells were cultured in Dulbecco's modified Eagle's medium (DMEM) containing $10 \%$ calf serum.The cells were harvested from the cell culture medium by incubating in a $0.5 \%$ trypsin solution for $2 \mathrm{~min}$. The cells were centrifuged, and the supernatant was discarded. The cells were resuspended in serum-supplemented DMEM and incubated at $37{ }^{\circ} \mathrm{C}$ and $5 \% \mathrm{CO}_{2}$.

The animal experiments were performed in accordance with the CAPN (China Animal Protection Law). The in vivo tumor suppression experiments were carried out using male BALB/c nude mice, aged 4-5 weeks, purchased from Zhejiang Academy of Medical Sciences. The A549 cells were inoculated subcutaneously at an injection volume of $0.1 \mathrm{~mL}$ containing $5 \times 10^{6}$ cells at the right axilla of BALB/c nude mice. The mice were assigned to six groups for different treatments when the tumor grew to a volume of around $100 \mathrm{~mm}^{3}$. Each treatment group was composed of five mice $(n=5)$ for antitumor therapy.

Preparation of mPEG- $b$-PLA-BODIPY/DTX (PPB/DTX) and mPEG- $b$-PLA/DTX (PP/DTX). The PPB/DTX and PP/DTX nanoparticles were prepared by the solvent evaporation method. In brief, copolymers and DTX were separately dissolved in tetrahydrofuran (THF) and then mixed. The mixture was slowly injected into an aqueous solution and stirred at room temperature overnight to ensure complete evaporation of THF.

TEM and DLS studies. The morphology of the PPB and PPB/DTX nanoparticles were revealed using TEM, respectively. TEM samples were prepared by drop-coating the solution of nanoparticles onto a carbon-coated copper grid. The corresponding solution was left to stand for $5 \mathrm{~min}$ and eliminated by a microporous membrane. The particle size of PPB and PPB/DTX at the concentration of $1.0 \mathrm{mg} / \mathrm{mL}$ were analyzed at $25^{\circ} \mathrm{C}$ by DLS. 
The stability study of PPB and PPB/DTX. PPB and PPB/DTX were incubated in PBS buffer and DMEM containing $10 \%$ serum for 2,4 and $8 \mathrm{~h}$, respectively. Then the particle sizes were analyzed by DLS.

Determination of drug loading content and in vitro release study. The drug loading content (LC) and encapsulation efficiency (EE) was calculated by determining the DTX concentrations in the formulations. The in vitro drug release behavior of PPB/DTX was studied using dialysis bag method in phosphatebuffered saline (PBS, pH 7.4) containing Tween $80(0.5 \% \mathrm{w} / \mathrm{v})$ or PBS containing Tween $80(0.5 \% \mathrm{w} / \mathrm{v})$ and $10 \%$ serum. Briefly, $3 \mathrm{~mL}$ of PPB/DTX (equivalent to $25 \mu \mathrm{g} / \mathrm{mL}$ of DTX) were sealed in dialysis bags (MCWO 6,000-8,000). The dialysis bags were added to the $50 \mathrm{~mL}$ conical tube containing $21 \mathrm{~mL}$ of drug release medium. The test conditions were a shaking speed of $100 \mathrm{rpm}$ and a temperature of $37{ }^{\circ} \mathrm{C} \pm$ $0.5^{\circ} \mathrm{C}$ and $44{ }^{\circ} \mathrm{C} \pm 0.5{ }^{\circ} \mathrm{C}$, respectively. The drug release of PP/DTX was determined at $37{ }^{\circ} \mathrm{C} \pm 0.5^{\circ} \mathrm{C}$ in the same condition. One milliliter of each sample was withdrawn at $0.5,1,2,4,6,8,12,24$ hours. The samples were filtered by $0.22 \mu \mathrm{m}$ filters and analyzed using a HPLC system. The mobile phase consisted of acetonitrile and water (55:45). The chromatographic conditions were as follows: an ultraviolet detector set at $230 \mathrm{~nm}$; a C18 column $(4.6 \times 150 \mathrm{~mm}$, ZORBAX SB-C18, Agilent, Santa Clara, CA, USA) operated at $25^{\circ} \mathrm{C} \pm 1.0^{\circ} \mathrm{C}$ and a flow rate of $0.6 \mathrm{~mL} / \mathrm{min}$.

Evaluation of cytotoxicity. The cytotoxicity of the PPB was evaluated by the 3-(4',5'-dimethylthiazol-2'yl)-2,5-diphenyl tetrazolium bromide (MTT) assay. Generally, the cells were seeded on a 96-well tissue culture plate at a density of $8 \times 10^{3}$ cells/well in $200 \mu \mathrm{L}$ of DMEM medium containing $10 \%$ serum for 18 h. The medium was replaced with $200 \mu \mathrm{L}$ of serum-free one containing serial dilutions of PPB solutions for $4 \mathrm{~h}$. The solutions were then replaced with $100 \mu \mathrm{L}$ of the serum-free medium containing $0.5 \mathrm{mg} / \mathrm{mL}$ MTT and incubated for another $4 \mathrm{~h}$. Finally, each well was replaced with $100 \mu \mathrm{L}$ of DMSO and measured spectrophotometrically on an ELISA plate reader (Model 550, Bio-Rad) at a wavelength $570 \mathrm{~nm}$. The relative cell growth $(\%)$ related to control cells cultured in the media without the polymer was calculated by the following formula:

$\mathrm{V} \%=\left([\mathrm{A}]_{\text {experimental }}-[\mathrm{A}]_{\text {blank }}\right) /\left([\mathrm{A}]_{\text {control }}-[\mathrm{A}]_{\text {blank }}\right) \times 100 \%$.

The cytotoxicity of NIR laser was also evaluated by MTT assay. The cells incubated in 96-well plate were irradiated by different luminous intensities of the $670 \mathrm{~nm}$ laser for $10 \mathrm{~min}$. The relative cell growth (\%) was calculated as mentioned above.

The efficacy of DTX was caculated by MTT assay. Briefly, the cells were seeded on a 96-well tissue culture plate at a density of $1 \times 10^{4}$ cells/well for $18 \mathrm{~h}$, and incubated with different formulations of DTX at defined concentrations for $48 \mathrm{~h}$. Then the relative cell growth (\%) was calculated. 
Cell apoptosis study. The A549 cells were seeded on a 12-well tissue culture plate at a density of $8 \times 10^{4}$ cells/well in $1.0 \mathrm{~mL}$ of DMEM medium containing $10 \%$ serum for $18 \mathrm{~h}$. The media were then replaced by $1 \mathrm{~mL}$ of serum free DMEM containing PPB/DTX and incubated for $4 \mathrm{~h}$ at a DTX concentration of 0.1 $\mu \mathrm{g} / \mathrm{mL}$. Then the medium were replaced by serum-containing DMEM and incubated for $48 \mathrm{~h}$. After $48 \mathrm{~h}$ incubation, the cells were washed by PBS, trypsinized, stained using a annexin V-FITC/PI apoptosis detection kit (beyotime Biotechnology). The cells were evaluated by the flow cytometer (BeckmanCoulter, USA).

Cell cycle study. The A549 cells were treated as mentioned in apoptosis study. After $48 \mathrm{~h}$ incubation, the cells were washed by PBS, trypsinized, fixed with $70 \%$ ethanol overnight and stained using PI. The cells were evaluated by the flow cytometer (Beckman-Coulter, USA).

Statistical analysis. The data were expressed as means \pm standard deviation. The statistical significance $(\mathrm{p}<0.05)$ was evaluated by the Student t-test. In all the tests, the statistical significance was set at $\mathrm{p}<$ 0.05 . 


\section{Synthesis of MPEG-b-PLA-BODIPY}

Synthesis of BODIPY-1. $\quad \mathrm{CH}_{2} \mathrm{Cl}_{2}(300 \mathrm{ml})$ was purged with $\mathrm{N}_{2}$ for 30 min. 1,4Hydroxyethoxybenzaldehyde (3.32 g, $20.0 \mathrm{mmol})$ and 2,4-dimethyl pyrrole (3.99 g, $42.0 \mathrm{mmol})$ were added. The color of the solution turned into redafter the addition of 6 drops of trifluoroacetic acid. The reaction mixture was stirred at roomtemperature for 12h. Then, tetrachloro-1,4-benzoquinone (4.90 g, 20 mmol) was added and thereaction mixture was stirred at room temperature for $4 \mathrm{~h}$. Then triethyl amine $(25 \mathrm{ml})$ and borontrifluoride diethyl etherate $(25 \mathrm{ml})$ were added sequentially. After stirring at room temperature for $8 \mathrm{~h}$, it was extracted with water. Organic layer was dried with $\mathrm{Na}_{2} \mathrm{SO}_{4}$ and evaporated underreduced pressure. The product was purified by silica gel column chromatography using $\mathrm{CH}_{2} \mathrm{Cl}_{2}$ /hexane $(50: 50, v / v)$. Fraction containing compound BODIPY-1 was collected then the solvent was removed under reduced pressure $(2.15 \mathrm{~g}, 28 \%)$. The ${ }^{1} \mathrm{H}$ NMR spectrum of BODIPY-1 is shown in Figure S1. ${ }^{1} \mathrm{H}$ NMR (300 MHz, chloroform- $d$, room temperature) $\delta(\mathrm{ppm}): 7.22(\mathrm{~d}, J=6 \mathrm{~Hz}, 2 \mathrm{H}), 7.06(\mathrm{~d}$, $J=6 \mathrm{~Hz}, 2 \mathrm{H}), 6.01(\mathrm{~s}, 2 \mathrm{H}), 4.19(\mathrm{t}, J=3 \mathrm{~Hz}, 2 \mathrm{H}), 4.05(\mathrm{t}, J=3 \mathrm{~Hz}, 2 \mathrm{H}), 2.59(\mathrm{~s}, 6 \mathrm{H}), 1.46(\mathrm{~s}, 6 \mathrm{H})$. The ${ }^{13} \mathrm{C}$ NMR spectrum of BODIPY-1 is shown in Figure S2. ${ }^{13} \mathrm{C}$ NMR (75 MHz, chloroform- $d$, room temperature) $\delta(\mathrm{ppm}): 159.63,156.67,145.34,141.37,131.70,129.22,127.19,115.53,115.43,69.33$, 61.39, 17.21, 16.04.HRESIMS: $m / z$ calcd for $[\mathrm{M}+\mathrm{H}]^{+} \mathrm{C}_{39} \mathrm{H}_{42} \mathrm{BF}_{2} \mathrm{~N}_{4} \mathrm{O}_{2}, 647.3293$, found 647.3304, error $1.7 \mathrm{ppm}$.
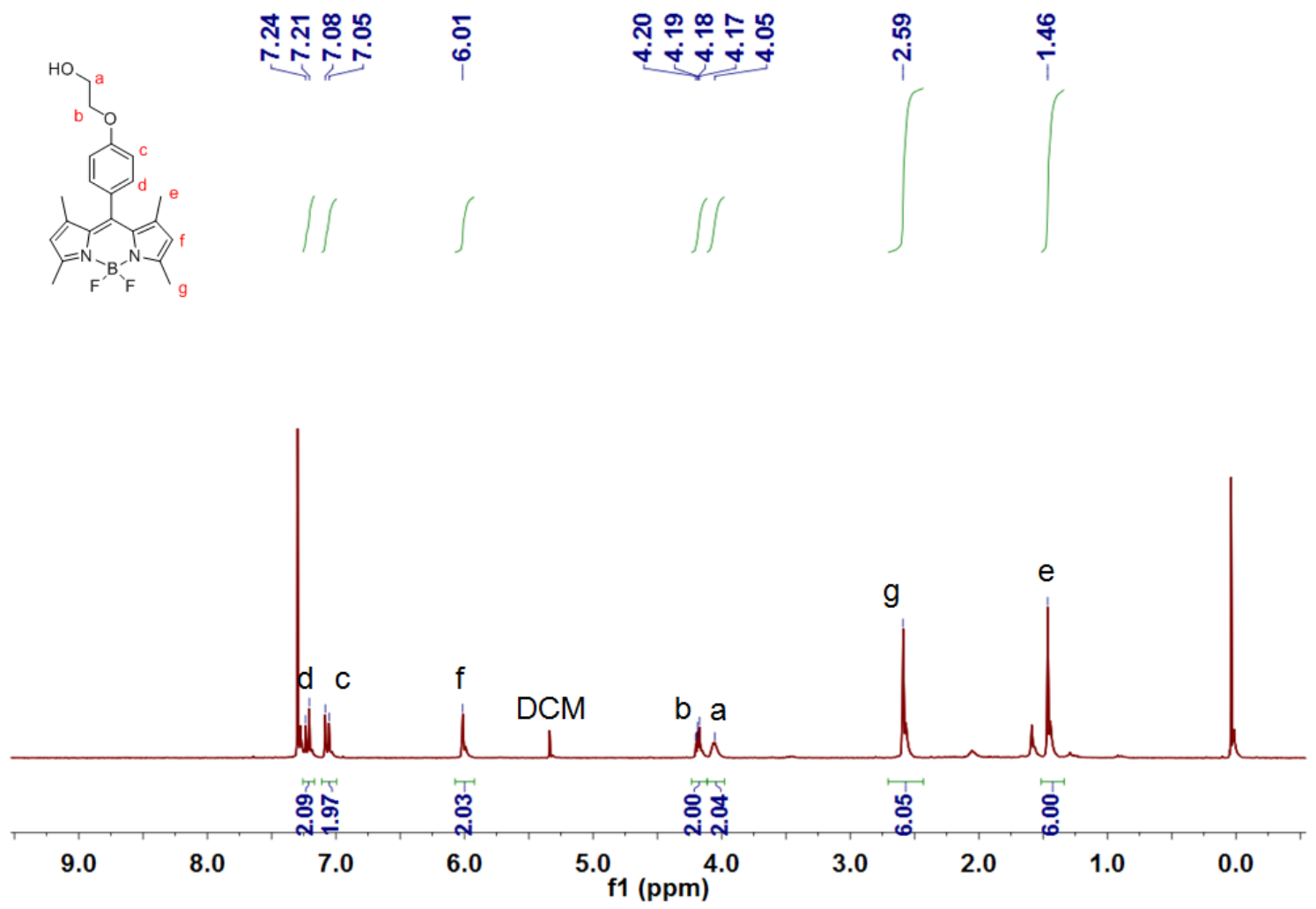

Figure S1. ${ }^{1} \mathrm{H}$ NMR spectrum (300 MHz, $\mathrm{CDCl}_{3}$, room temperature) of compound BODIPY-1. 


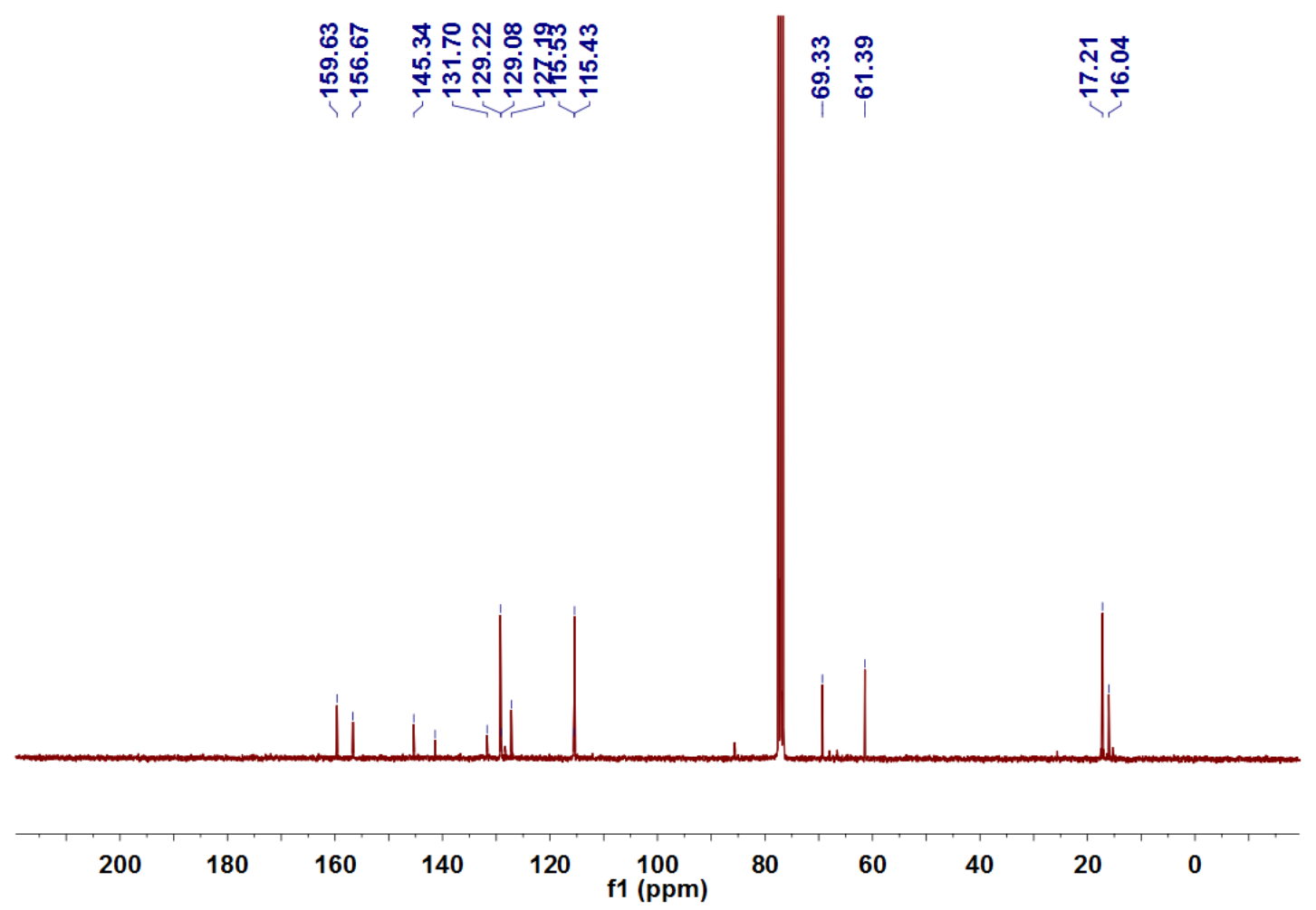

Figure S2. ${ }^{13} \mathrm{C}$ NMR spectrum $\left(75 \mathrm{MHz}, \mathrm{CDCl}_{3}\right.$, room temperature) of compound BODIPY-1.

Synthesis of BODIPY-2. A mixture of BODIPY-1 (1.92 g, $5.00 \mathrm{mmol}$ ) and dimethylaminobenzaldehyde $(2.98 \mathrm{~g}, 20 \mathrm{mmol})$ were refluxed in a mixture of toluene $(100 \mathrm{~mL})$, glacialacetic acid $(2 \mathrm{~mL})$, piperidine (2.4 mL) and small amount of $\mathrm{Mg}\left(\mathrm{ClO}_{4}\right)_{2}$. The formed water during the reaction was removed azeotropically by heating overnight in a Dean-Stark apparatus. After $6 \mathrm{~h}$, the crude product was concentrated under vacuum and then was purified by column chromatography over silica gelusing EtOAc/hexane $(1: 2, v / v)$ solvent system as eluent. The green colored fraction was collected $(516 \mathrm{mg}$, $16 \%)$.The ${ }^{1} \mathrm{H}$ NMR spectrum of BODIPY-2 is shown in Figure S3. ${ }^{1} \mathrm{H}$ NMR $\left(300 \mathrm{MHz}\right.$, DMSO- $d_{6}$, room temperature) $\delta(\mathrm{ppm}): 7.46(\mathrm{~d}, J=6 \mathrm{~Hz}, 4 \mathrm{H}), 7.40(\mathrm{~s}, 2 \mathrm{H}), 7.33(\mathrm{~s}, 2 \mathrm{H}), 7.28(\mathrm{~d}, J=6 \mathrm{~Hz}, 2 \mathrm{H}), 7.10$ $(\mathrm{d}, J=6 \mathrm{~Hz}, 2 \mathrm{H}), 6.87(\mathrm{~s}, 2 \mathrm{H}), 6.80(\mathrm{~d}, J=6 \mathrm{~Hz}, 4 \mathrm{H}), 4.36(\mathrm{t}, J=6 \mathrm{~Hz}, 2 \mathrm{H}), 4.04(\mathrm{t}, J=6 \mathrm{~Hz}, 2 \mathrm{H}), 3.01(\mathrm{~s}$, 12H), 1.45 (s, 6H). The ${ }^{13} \mathrm{C}$ NMR spectrum of BODIPY-2 is shown in Figure $\mathrm{S} 4 .{ }^{13} \mathrm{C}$ NMR $(75 \mathrm{MHz}$, DMSO- $d_{6}$, room temperature) $\delta(\mathrm{ppm}): 152.48,151.42,141.09,137.42,133.08,130.24,129.09,124.37$, 118.06, 117.99, 115.43, 112.67, 68.07, 61.12, 33.00, 29.20, 25.94, 25.82, 14.81.HRESIMS: $\mathrm{m} / \mathrm{z}$ calcd for $[\mathrm{M}+\mathrm{H}]^{+} \mathrm{C}_{39} \mathrm{H}_{42} \mathrm{BF}_{2} \mathrm{~N}_{4} \mathrm{O}_{2}, 647.3293$, found 647.3304, error $1.7 \mathrm{ppm}$. 


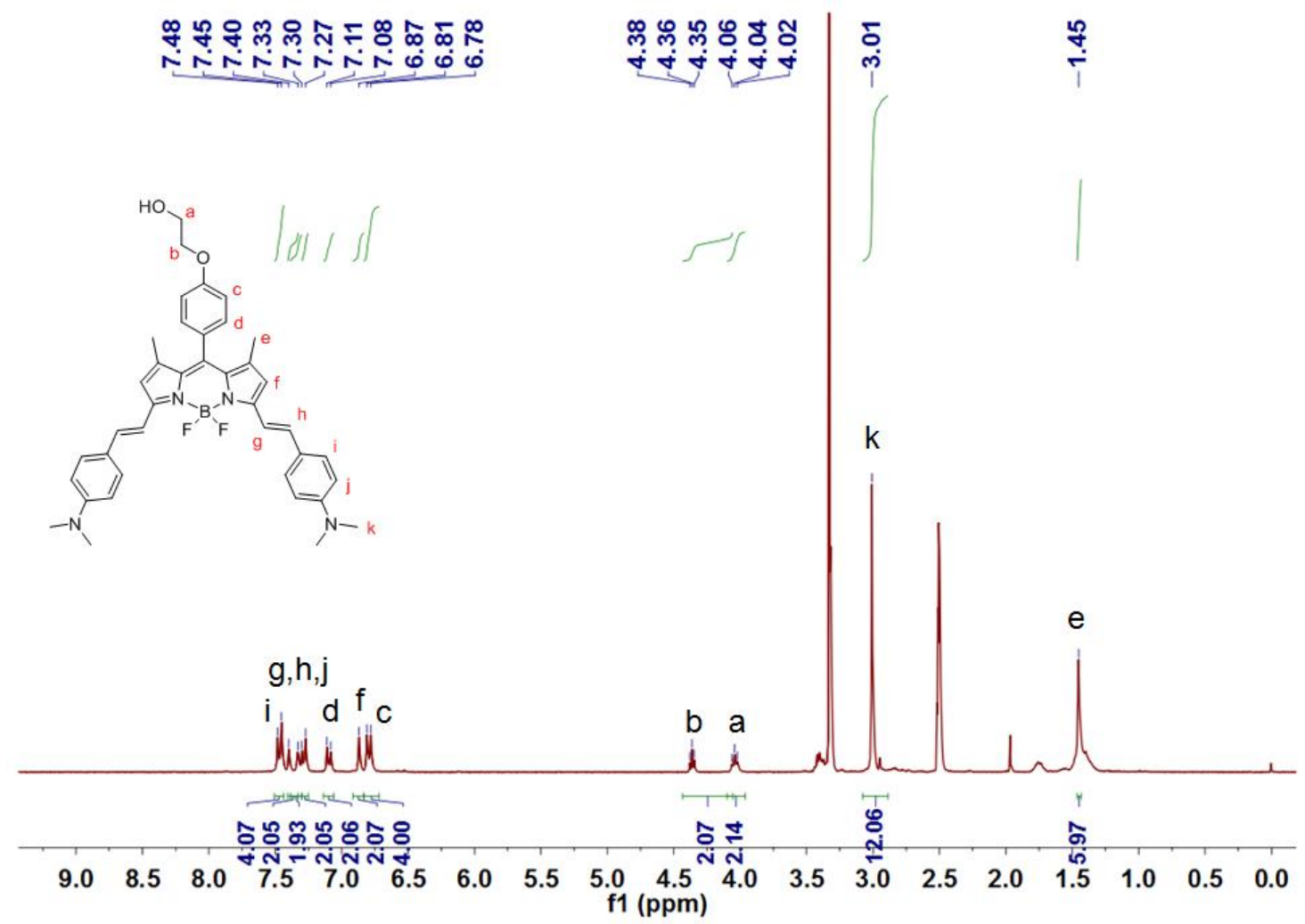

Figure S3. ${ }^{1} \mathrm{H}$ NMR spectrum (300 MHz, DMSO- $d_{6}$, room temperature) of compound BODIPY-2.

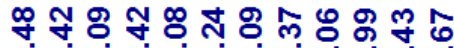

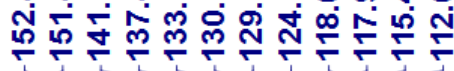
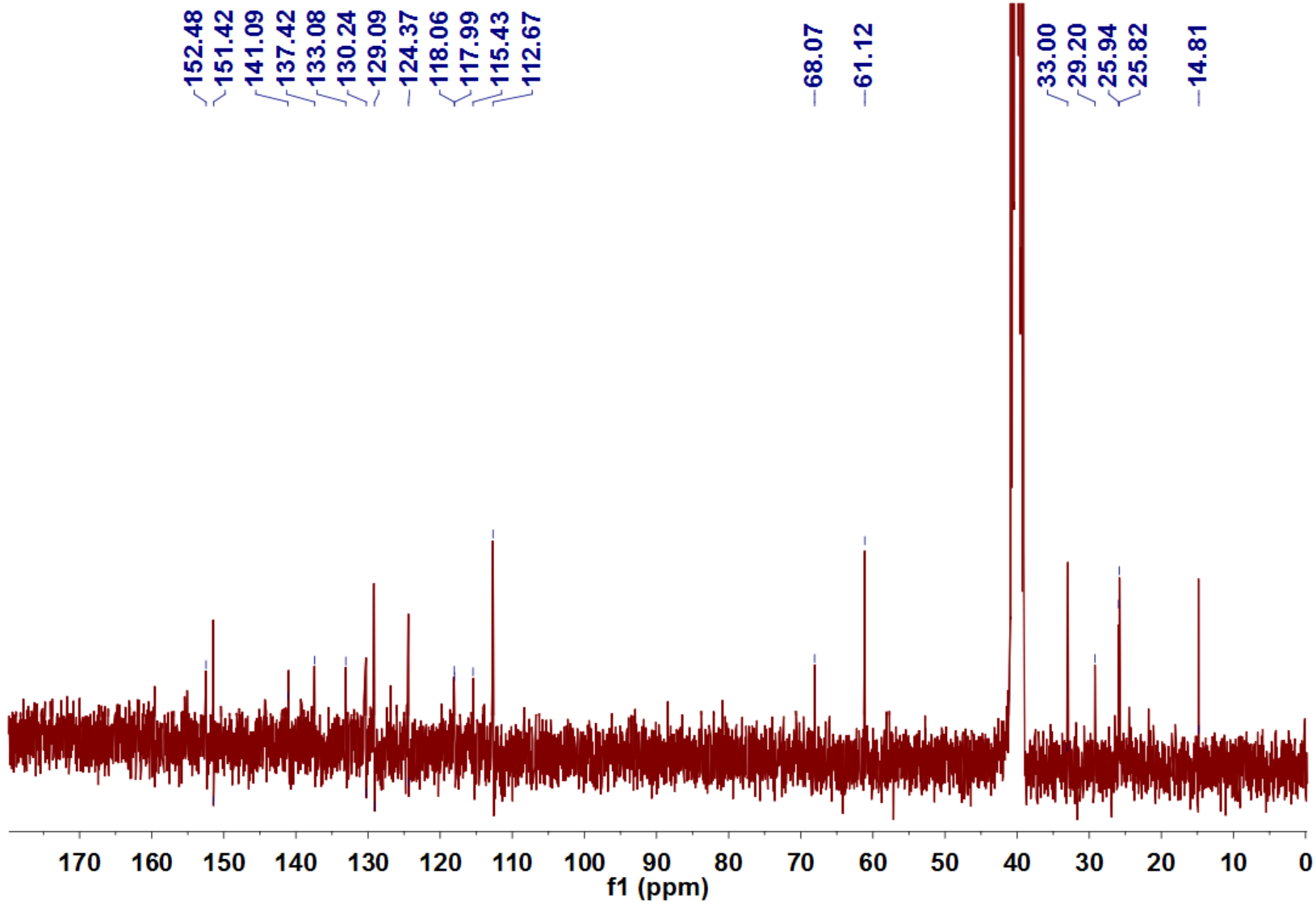

Figure S4. ${ }^{13} \mathrm{C}$ NMR spectrum (75 MHz, DMSO- $d_{6}$, room temperature) of compound BODIPY-2. 
Synthesis of mPEG- $\boldsymbol{b}$-PLA-OH: mPEG-OH (2.50 g, $0.500 \mathrm{mmol})$ and lactide $(5.00 \mathrm{~g}, 34.7 \mathrm{mmol})$ were solubilized in anhydrous $\mathrm{CH}_{2} \mathrm{Cl}_{2}(8 \mathrm{~mL})$. 1,8-diazabicyclo[5.4.0]undec-7-ene (100 $\left.\mu \mathrm{L}\right)$ was added into the mixture under stirring. After $15 \mathrm{~min}$, the reaction was quenched by adding $1 \mathrm{~mL}$ acetic acid. The resulting solution was precipitated into an excess of diethyl ether. After filtration, the sediments was dissolved in $\mathrm{CH}_{2} \mathrm{Cl}_{2}$ and precipitated into an excess of diethyl ether; the above dissolution-precipitation cycle was repeated three times. After drying in a vacuum oven overnight at room temperature, mPEG-b-PLA-OH was obtained as a white solid (yield: $96 \%$ ). The GPC curve of mPEG- $\boldsymbol{b}$-PLA-OH is shown in Figure S5, and the ${ }^{1} \mathrm{H}$ NMR spectrum of mPEG- $\boldsymbol{b}$-PLA-OH is shown in Figure S6 (300 MHz, chloroform- $d$, room temperature). From ${ }^{1} \mathrm{H}$ NMR spectrum, the molecular weight was calculated to be $14.4 \mathrm{kDa}$.

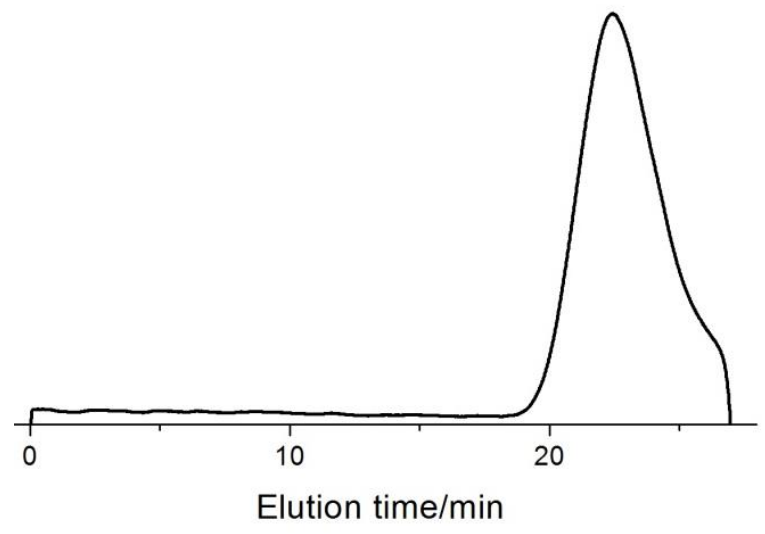

Figure S5. The GPC curve of mPEG-b-PLA-OH.

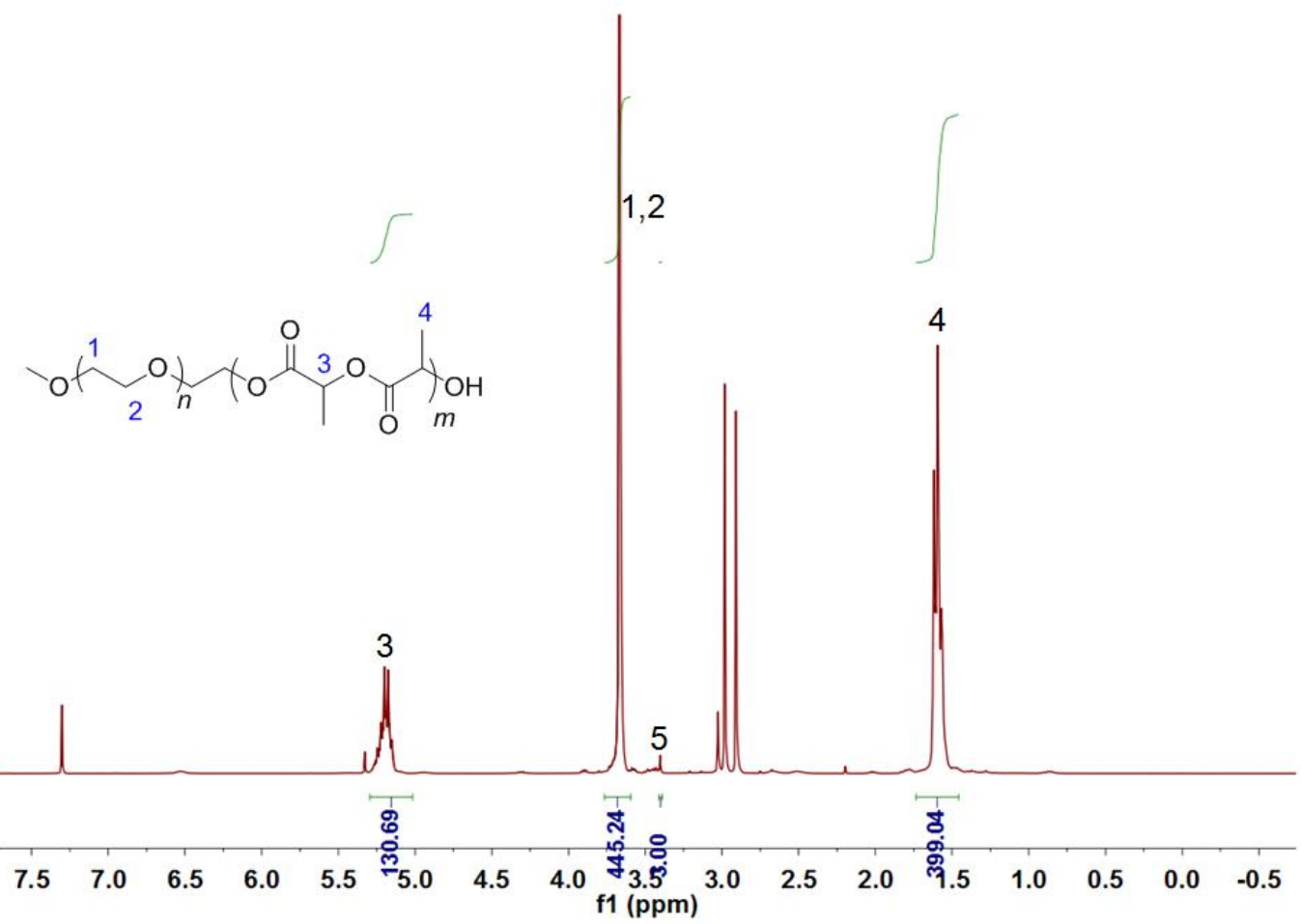

Figure S6. ${ }^{1} \mathrm{H}$ NMR spectrum (300 MHz, $\mathrm{CDCl}_{3}$, room temperature) of mPEG- $\boldsymbol{b}$-PLA-OH. 
Synthesis of mPEG- $\boldsymbol{b}$-PLA-COOH: Succinic anhydride (200 mg, $2.00 \mathrm{mmol}$ ) was added into the anhydrous $\mathrm{CH}_{2} \mathrm{Cl}_{2}$ solution containing mPEG- $\boldsymbol{b}$-PLA-OH $(1.44 \mathrm{~g}, 0.100 \mathrm{mmol})$ and DMAP $(24.5 \mathrm{mg}$, $2.00 \mathrm{mmol}$ ). After stirring for $12 \mathrm{~h}$, the solution was poured into an excess of diethyl ether. After filtration, the sediments was dissolved in $\mathrm{CH}_{2} \mathrm{Cl}_{2}$ and precipitated into an excess of diethyl ether; the above dissolution-precipitation cycle was repeated three times. After drying in a vacuum oven overnight at room temperature, mPEG- $\boldsymbol{b}$-PLA-COOH was obtained as a white solid (yield: $89 \%$ ). The ${ }^{1} \mathrm{H}$ NMR spectrum of mPEG- $\boldsymbol{b}$-PLA-COOH is shown in Figure S7 (300 MHz, DMSO- $d_{6}$, room temperature).

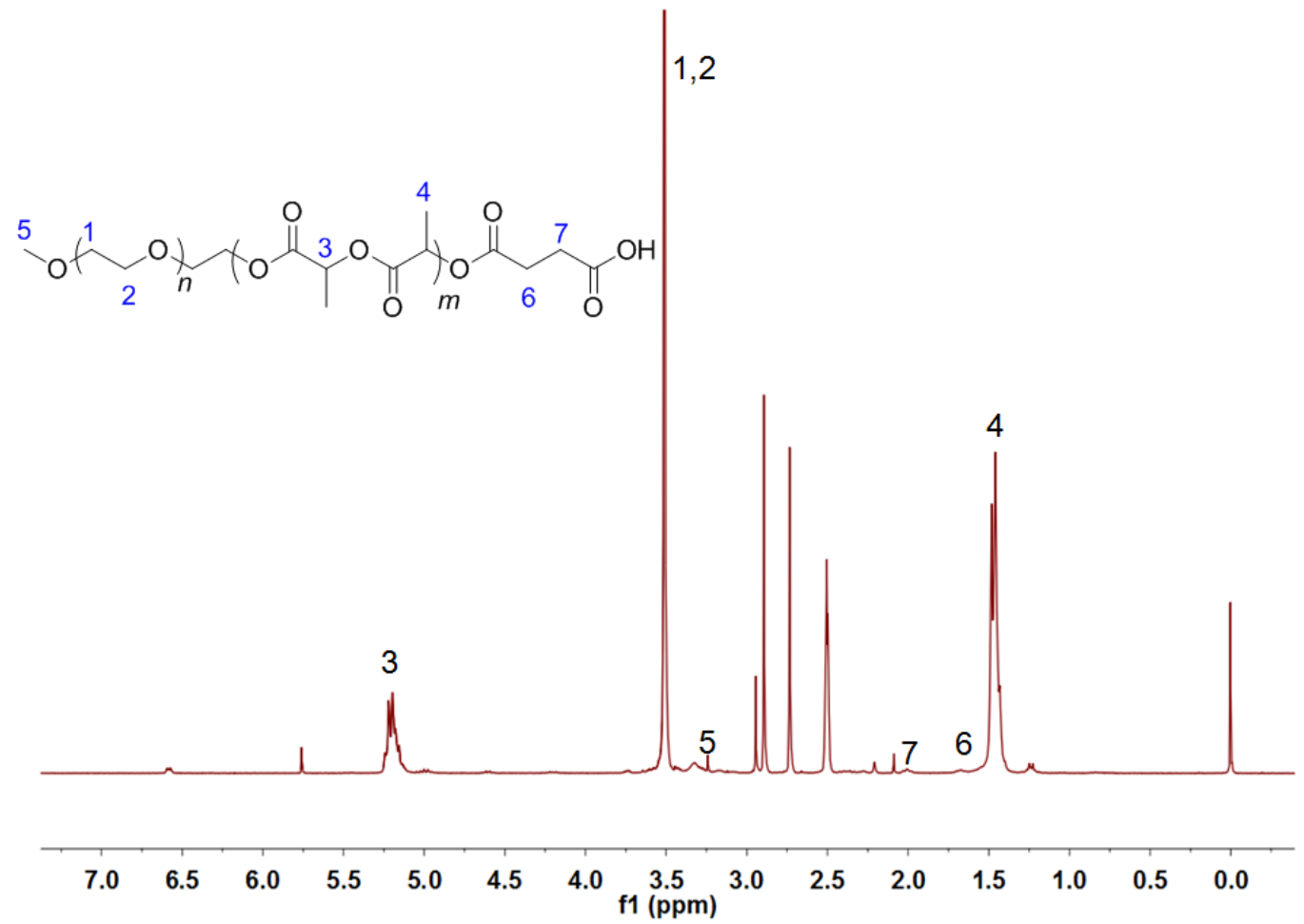

Figure S7. ${ }^{1} \mathrm{H}$ NMR spectrum (300 MHz,DMSO- $d_{6}$, room temperature) of mPEG-b-PLA-COOH.

Synthesis of mPEG- $\boldsymbol{b}$-PLA-BODIPY: mPEG- $\boldsymbol{b}$-PLA-COOH (750 mg, $50.0 \mu \mathrm{mol})$, BODIPY-2 $(323$ $\mathrm{mg}, 500 \mu \mathrm{mol}$ ) was added into the anhydrous $\mathrm{CH}_{2} \mathrm{Cl}_{2}$ solution containing $N$-(3-dimethylaminopropyl)- $N^{\prime}$ ethylcarbodiimide hydrochloride $(191 \mathrm{mg}, 1.00 \mathrm{mmol})$ and DMAP (50.0 mg). After stirring for $12 \mathrm{~h}$, the solution was poured into an excess of diethyl ether. After filtration, the sediments was dissolved in $\mathrm{CH}_{2} \mathrm{Cl}_{2}$ and precipitated into an excess of diethyl ether; the above dissolution-precipitation cycle was repeated three times. After drying in a vacuum oven overnight at room temperature, mPEG- $\boldsymbol{b}$-PLABODIPY was obtained as a green solid (yield: $89 \%$ ). The ${ }^{1} \mathrm{H}$ NMR spectrum of mPEG- $\boldsymbol{b}$-PLABODIPY is shown in Figure S8 (300 MHz, DMSO- $d_{6}$, room temperature). 


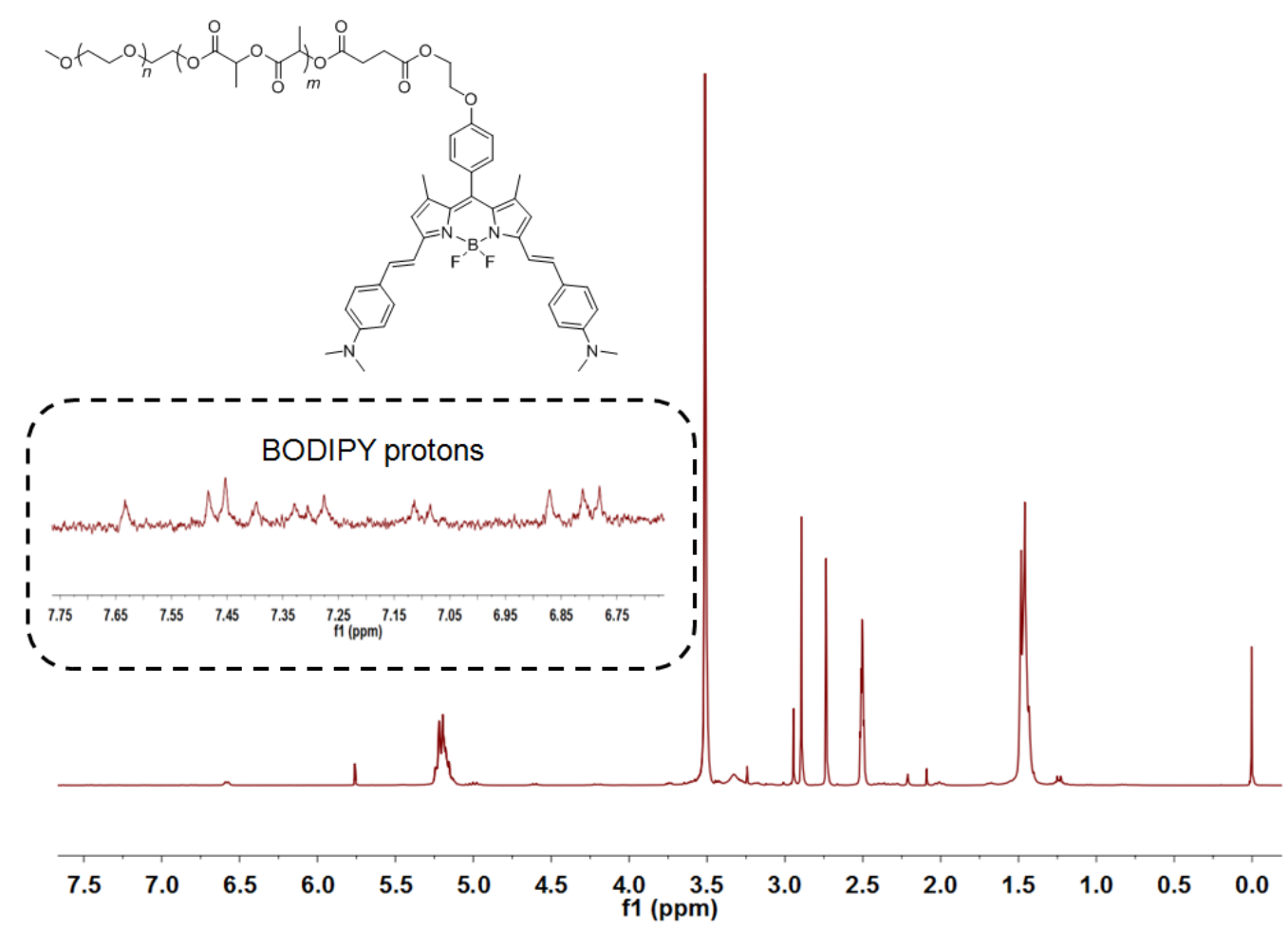

Figure S8. ${ }^{1} \mathrm{H}$ NMR spectrum (300 MHz,DMSO- $d_{6}$, room temperature) of mPEG- $\boldsymbol{b}$-PLA-BODIPY.

3. UV-vis absorption spectrum of BODIPY-2

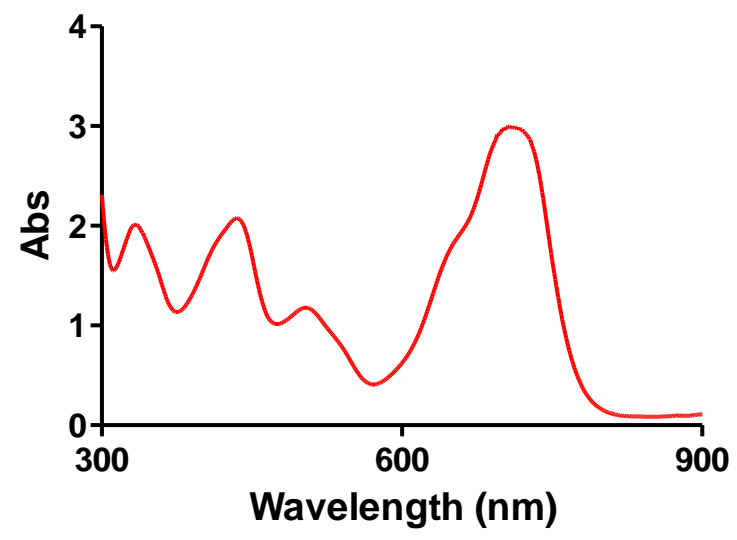

Figure S9. UV-vis absorption spectrum of BODIPY-2.

4. In vitro drug release

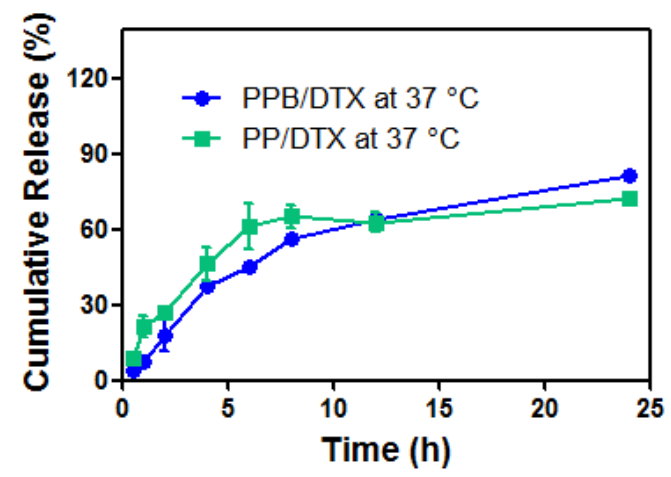

Figure S10. Drug release of PP/DTX and PPB/DTX at the temperature of $37^{\circ} \mathrm{C}$. 
5. Cytotoxicity evaluation.

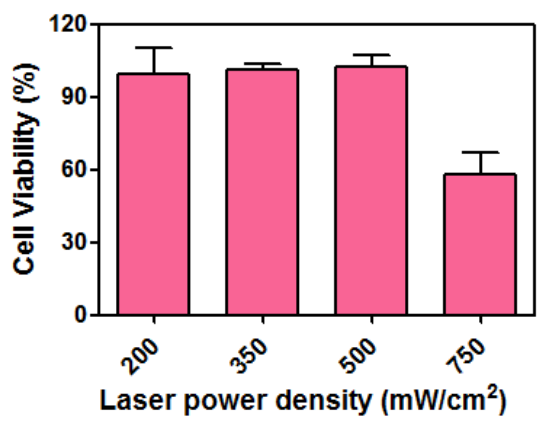

Figure S11. Cytotoxicity of laser at different power density in A549 cells by MTT assay.

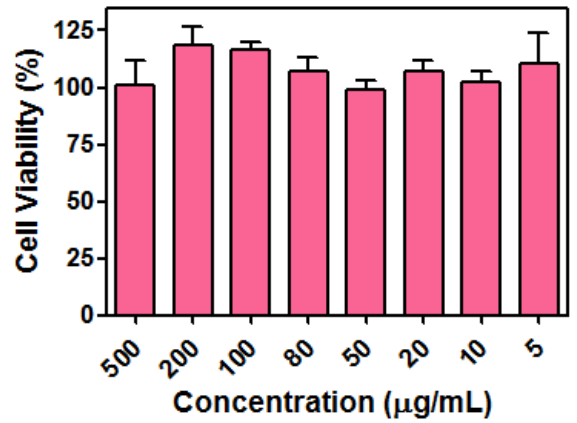

Figure S12. Cytotoxicity of PPB nanoparticles in A549 cells by MTT assay.

6. In vivo photothermal effect

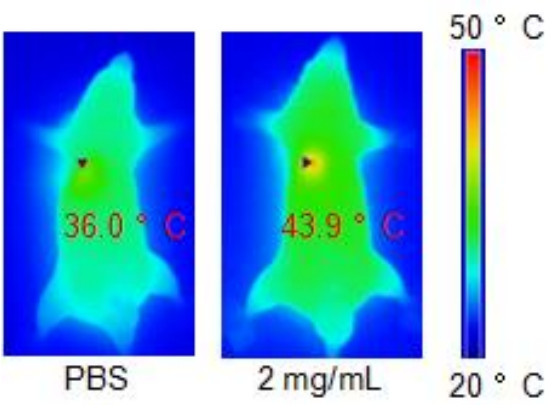

Figure S13. Thermography of tumor-bearing mice injected with PPB after irradiation with $670 \mathrm{~nm}$ laser at a power density of $500 \mathrm{~mW} / \mathrm{cm}^{2}$ for $10 \mathrm{~min}$. PBS was used as a control. 
7. In vivo tumor penetration

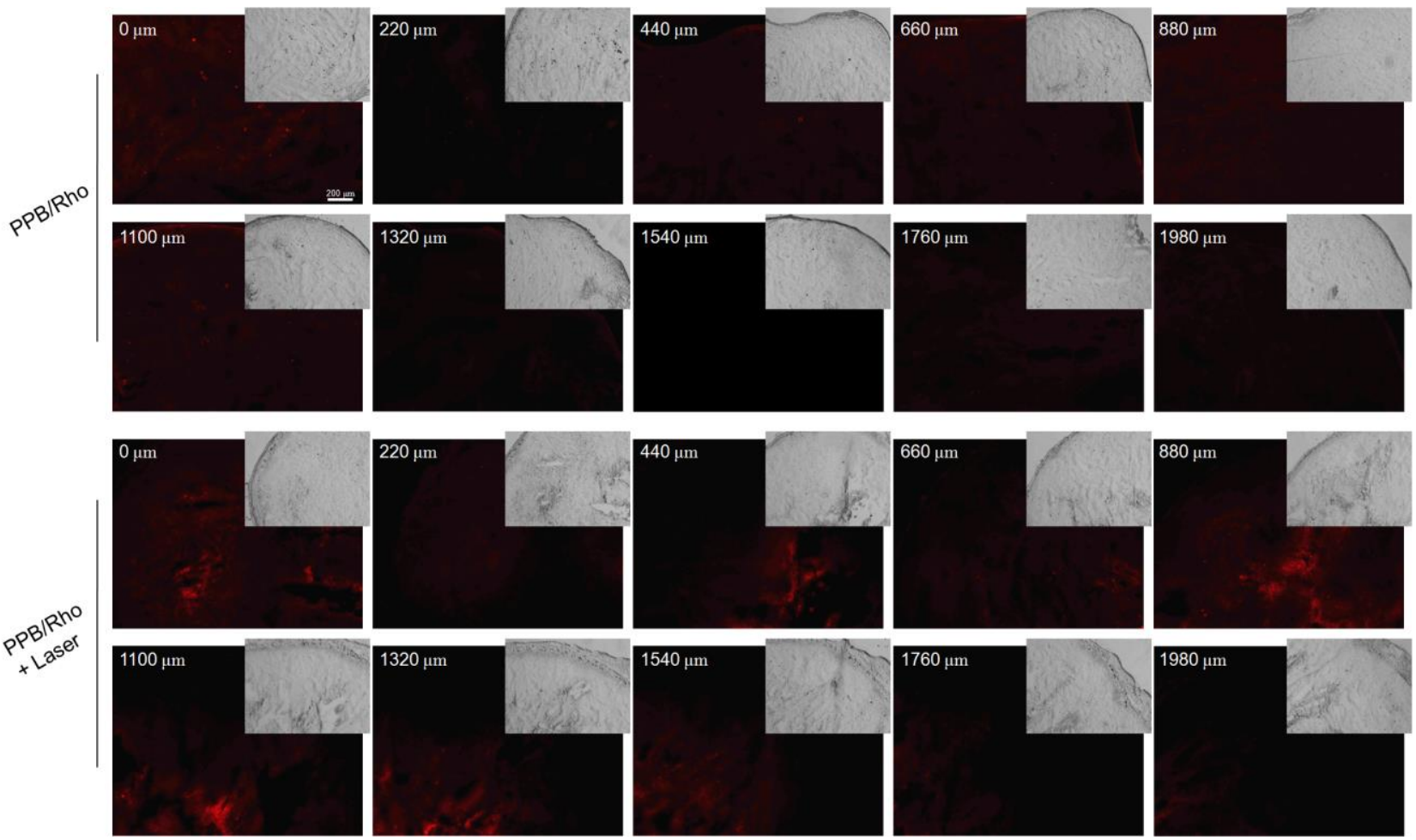

Figure S14. Frozen sections of mice tumors injected with $\mathrm{PPB} / \mathrm{Rho}$ and $\mathrm{PPB} / \mathrm{Rho}$ with laser irradiation. The sections were taken every $200 \mu \mathrm{m}$ from the top to the bottom, each section being $20 \mu \mathrm{m}$ thick. Scale bar $=200 \mu \mathrm{m}$.

\section{Histopathology and immunohistochemistry of tumors}

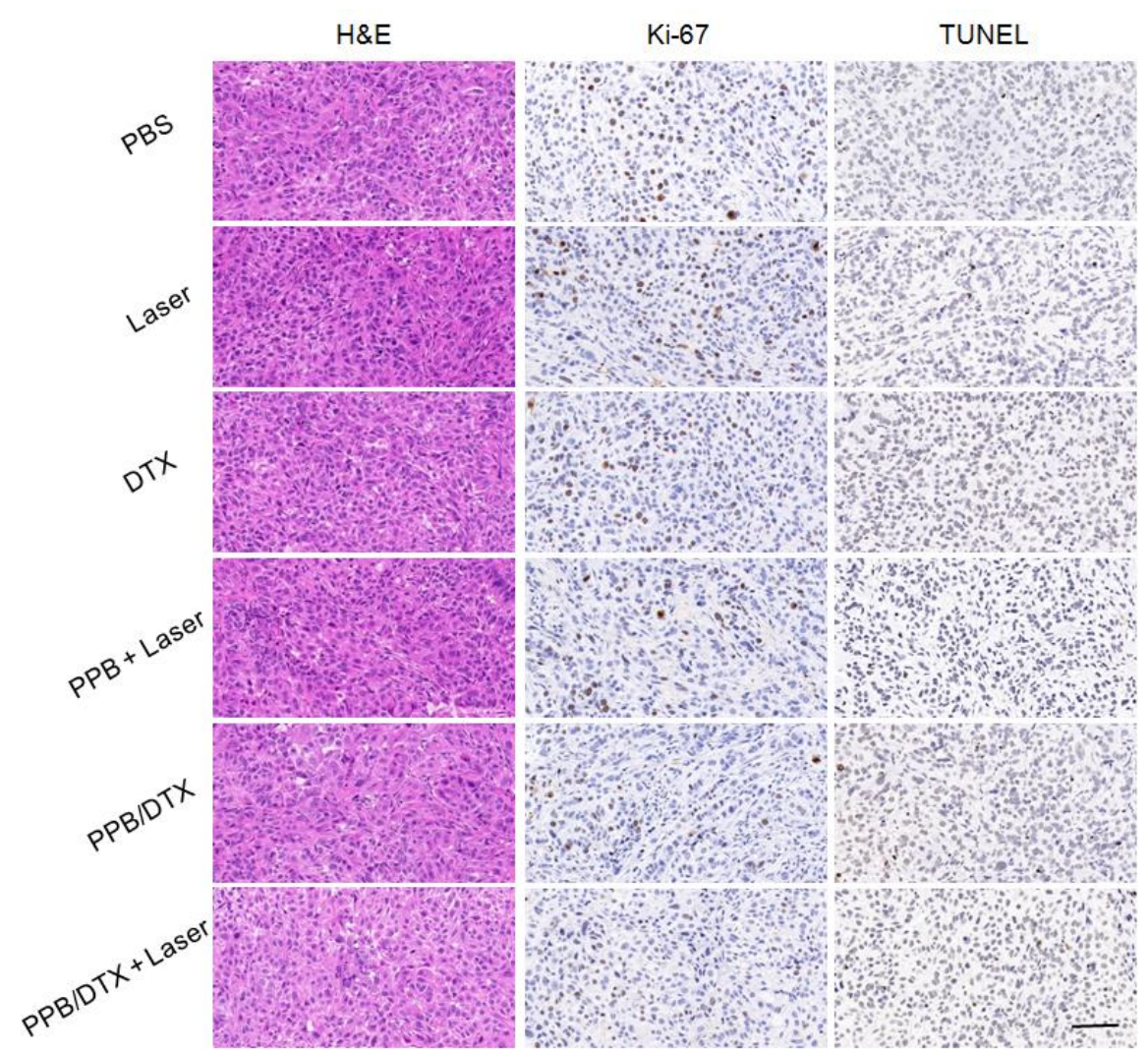

Figure S15. H\&E, Ki-67 and TUNEL analysis of the tumor tissues from each group. Scale bar $=50 \mu \mathrm{m}$. 
9. Body weight analysis

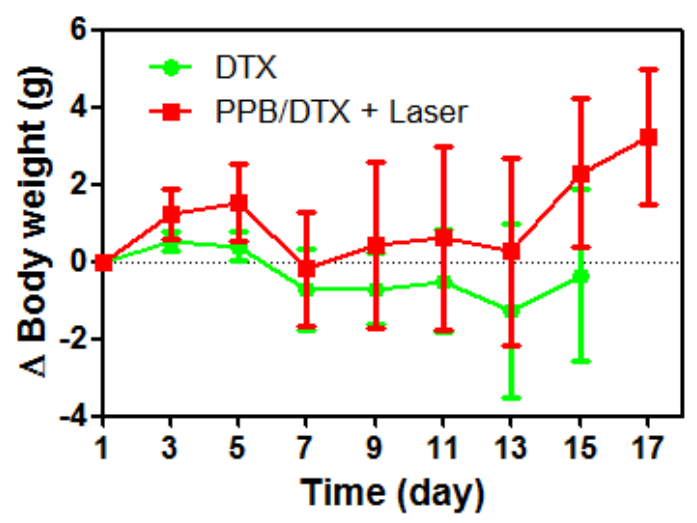

Figure S16. Body weight curves of mice treated with DTX or PPB/DTX + laser.

10. Histopathology of organs

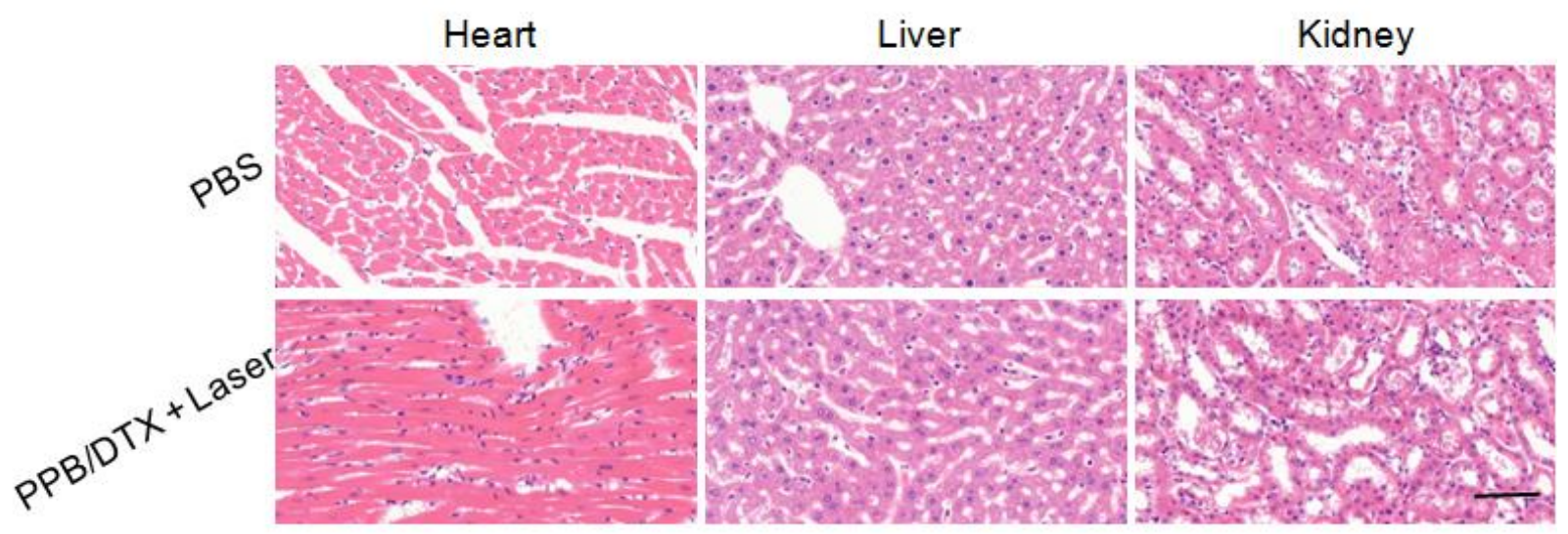

Figure S17. H\&E staining of heart, liver and kidney of PBS group and PPB/DTX + laser group. Scale bar $=50 \mu \mathrm{m}$. 